\title{
Characterization of extensively drug-resistant Mycobacterium tuberculosis isolates circulating in Siberia
}

\author{
Maya A Dymova ${ }^{1,2^{*}}$, Andrey G Cherednichenko ${ }^{3}$, Olga I Alkhovik ${ }^{3}$, Eugeny A Khrapov ${ }^{1}$, Tatjana I Petrenko ${ }^{3}$ \\ and Maxim L Filipenko ${ }^{1,2}$
}

\begin{abstract}
Background: The spread of multidrug-resistant (MDR) and extensively drug-resistant (XDR) Mycobacterium tuberculosis compromises effective control of tuberculosis (TB) in Siberia. Early identification of drug-resistant isolates is, therefore, crucial for effective treatment of this disease. The aim of this study was to conduct drug susceptibility testing and identify mutations in drug resistance genes in clinical isolates of $M$. tuberculosis from some TB patients presenting for treatment in Siberia.

Methods: Thirty randomly selected clinical isolates of $M$. tuberculosis were obtained from the Novosibirsk Research Institute of Tuberculosis, Russia. Isolates were screened for drug resistance and characterized by variable number of tandem repeats (VNTR)-typing using 15 standard and four additional loci. Deligotyping on multiple large sequences was performed using 10 loci.

Results: Twenty-nine of the isolates were assigned XDR status. Twenty-eight isolates belonged to the M. tuberculosis Beijing family, from which 11 isolates were considered the M11 type (39\%), two the M2 type (7\%), and one the M33 type (3\%). Seventeen isolates (60.7\%) from this family exhibited unique genetic patterns. The remaining two isolates belonged to the Latino-American Mediterranean family. Gene sequences ( $r p o B, k a t G$, rrs, rps L, tlyA, gidB, gyrA, gyrB) were analyzed to identify mutations that confer resistance to rifampicin, isoniazid, amikacin, kanamycin, capreomycin, and ofloxacin. The most common mutations among the XDR isolates were S531L in RpoB, S315T in KatG, various codon 94 mutations in gyrA, A90V in GyrA, K43R in RpsL, and $1401 \mathrm{~A} \rightarrow \mathrm{G}$ in rrs; these confer resistance to rifampicin, isoniazid, ofloxacin, streptomycin and kanamycin/capreomycin, respectively. There was high congruence between the two typing methods (VNTR typing and deligotyping) and RD105, RD149, RD152, RD181, and RD207 regions of difference were absent from the 28 Beijing family isolates.

Conclusions: Deligotyping can be used for rapid and reliable screening of $M$. tuberculosis isolates, followed by more in-depth genotyping. Identification of Beijing family isolates with extensive drug resistance confirms that such strains have epidemiological importance in Siberia. Rapid detection of mutations that lead to drug resistance should facilitate selection of effective drug therapies, and the development of early prevention strategies to combat this infection.
\end{abstract}

Keywords: Mycobacterium tuberculosis, Multidrug resistance, Drug-resistance mutations, Genotyping

\footnotetext{
*Correspondence: maya.a.rot@gmail.com

${ }^{1}$ Institute of Chemical Biology and Fundamental Medicine (ICBFM), Siberian Branch of The Russian Academy of Sciences (SB RAS), Novosibirsk, Russia

${ }^{2}$ Novosibirsk State University (NSU), Novosibirsk, Russia

Full list of author information is available at the end of the article
} 


\section{Background}

The dissemination of extensively drug resistant (XDR) Mycobacterium tuberculosis poses a threat to the fight against tuberculosis (TB). According to a 2012 WHO report, XDR-TB has been identified in 84 countries where it comprises $9 \%$ of all cases that are multidrug resistant (MDR) [1] from a worldwide figure of 310,000 in 2011. From this, $60 \%$ of all MDR-TB cases were from Russia, India, China, and South Africa. In Russia in particular, the number of cases with a confirmed diagnosis of MDR-TB in 2011 was 44,000 [1], while the 2011 Novosibirsk Research Institute of Tuberculosis report for the Novosibirsk region of Russia revealed that the number of cases with primary MDR- and XDR-TB was 272 (28.7\%) and 4 (0.4\%), respectively. What is particularly alarming is that the rapid increase in MDR-TB in the Novosibirsk region, which in 2005 was $43 / 100,000$, and in 2011 was $58.3 / 100,000$ of the population. In Siberia from 2005 to 2011 the increase was from 34.0 to $46.5 / 100,000$ of the population, while the Far Eastern Federal Districts rose from 20.0/100,000 to 38.3/ 100,000 of the population.

The causes of XDR TB are multi-factorial and include incorrect treatment regimens, violations of chemotherapy regimens, late diagnosis, and poor infection control [2]. $M$. tuberculosis can rapidly accumulate non-synonymous mutations in genes associated with the emergence of drug resistance. The term XDR itself relates to the involvement of simultaneous resistance to first-line drugs (e.g., isoniazid and rifampicin), one of the injectable second-line drugs (e.g., amikacin, capreomycin, and kanamycin), and any of a number of ofloxacin-based drugs. Rifampicin resistance in $M$. tuberculosis is caused by mutations in the core region of the $r p o B$ gene, while isoniazid resistance is associated with mutations in the $k a t G, \operatorname{inh} A, \operatorname{ahpC}$, and oxyR genes [3]. Other anti-TB drugs for which resistance has developed include ethambutol (involving mutations in the $e m b A B$ locus), streptomycin (involving nucleotide changes in the gidB and rpsL genes) [4], ofloxacin (involving the gyrA and $g y r B$ genes), and amikacin and capreomycin (involving the rrs gene encoding 16S rRNA, and also in the $t l y A$ gene encoding hemolysin) [5].

The aims of this study were to: 1) genotype and characterize multidrug resistance in $M$. tuberculosis isolates using an extended set of loci for variable number of tandem repeats (VNTR)-typing and by deligotyping; and 2) detect the spectrum and frequency of mutations associated with the emergence of XDR in M. tuberculosis.

\section{Methods}

\section{M. tuberculosis isolates}

This was a cross-sectional study, examining the drug susceptibility and molecular-genetic features of XDR isolates in Siberia and Far East of Russia. The Novosibirsk Research Institute of Tuberculosis (NRIT) acts as the national referral center for TB in Far East and Siberia region of Russia. Under the National Tuberculosis Control program, randomly selected patients with the MDR and relapse tuberculosis are referred to the NRIT for evaluation and treatment. $372 \mathrm{MDR}$ isolates (31 XDR) were recovered from January 2011 to February 2012. We analyzed 30 consecutive XDR-TB clinical isolates correspond to $1.6 \%$ of all the XDR-TB ones isolated in Far East and Siberia region of Russia. All analysed MTB were recovered from individual patients with pulmonary TB who were treated at NRIT from January 2011 to February 2012 were included in study. Despite small size of tested sample set percentage of XDR among MDR isolates (8\%) did not showed statistically significant differences $(\mathrm{p}$-value $=0.76)$ with total one in supervised region (1858 XDR/24400 MDR during the same period of time). All isolates were obtained from patients already receiving TB treatment for more than 1 month. Only three patients were treated for less than 1 month. Fourteen patients were admitted to hospital from the Novosibirsk region, two from the Republic of Khakassia, two from Kemerovo Oblast, two from Omsk Oblast, two from Krasnoyarsk Krai, two from Kamchatka, and one each from Tomsk, Tuva Republic, the Jewish Autonomous Region, Chita, and Altai Republic. This study had bioethical approval from the local committee on medical ethics. Informed consent was received from each patient in the study.

\section{Bacterial culture and antibiotic susceptibility testing}

Drug resistance was determined by calculating the minimal inhibitory concentrations (MIC) using the Bactec MGIT 960 system (BD, New Jersey, USA) with standard concentrations of drugs as follows: isoniazid $(0.1 \mu \mathrm{g} / \mathrm{ml})$, rifampicin $(1 \mu \mathrm{g} / \mathrm{ml})$, pyrazinamide $(100 \mu \mathrm{g} / \mathrm{ml})$, streptomycin $(1 \mu \mathrm{g} / \mathrm{ml})$, ethambutol $(5 \mu \mathrm{g} / \mathrm{ml})$, kanamycin $(1 \mu \mathrm{g} / \mathrm{ml})$, amikacin $(1 \mu \mathrm{g} / \mathrm{ml})$, ethionamide $(5 \mu \mathrm{g} / \mathrm{ml})$, ofloxacin $(2 \mu \mathrm{g} / \mathrm{ml})$, and capreomycin $(2.5 \mu \mathrm{g} / \mathrm{ml})$.

\section{DNA extraction}

DNA was isolated from $M$. tuberculosis cultures at NRIT, as described previously [6].

\section{PCR amplification and DNA sequencing of genes associated with drug-resistance}

PCR amplification was performed in $20-\mu$ l volumes containing $65 \mathrm{mM}$ Tris- $\mathrm{HCl}$ (pH 8.9), $16 \mathrm{mM}(\mathrm{NH} 4)_{2} \mathrm{SO} 4$, 0.05\% Tween 20, $2.5 \mathrm{mM} \mathrm{MgCl}_{2}, 0.1 \mathrm{mM}$ dNTPs, $1 \mu \mathrm{M}$ gene-specific oligonucleotide primers (Table 1), $1 \mathrm{U}$ Taq DNA polymerase, and 1-10 ng of $M$. tuberculosis genomic DNA. The oligonucleotide primer sequences are shown in Table 1. Reactions were carried out in a Tertsik amplifier (DNA Technology, Russia) using an initial denaturation step of $96^{\circ} \mathrm{C}$ for $3 \mathrm{~min}$, followed by 38 cycles of denaturation at $95^{\circ} \mathrm{C}$ for $10 \mathrm{~s}$, annealing at $64^{\circ} \mathrm{C}$ for $10 \mathrm{~s}$, and 
Table 1 Oligonucleotide primers

\begin{tabular}{|c|c|}
\hline Primer & Nucleotide structure \\
\hline ETRA1 & 5'-GATTGAGGGGATCGTGATTGG-3' \\
\hline ETRA2 & 5'-AAATCGGTCCCATCACCTTCTTAT-3' \\
\hline ETRB1 & 5'-GCGAACACCAGGACAGCATCATG-3' \\
\hline ETRB2 & 5'-GGCATGCCGGTGATCGAGTGG-3' \\
\hline ETRC1 & 5'-GTGAGTCGCTGCAGAACCTGCAG-3' \\
\hline ETRC2 & 5'-GGCGTCTTGACCTCCACGAGTG-3' \\
\hline MIRU02U & 5'-CAGGACACGGGTTCTACTG-3' \\
\hline MIRU02R & 5'-GGACTAGGTCGAGGTTGTGTC-3' \\
\hline MIRU04U & 5'-CAGGTCACAACGAGAGGAAGAGC-3' \\
\hline MIRU04R & 5'-GCGGATCGGCCAGCGACTCCTC-3' \\
\hline MIRU10U & 5'-GACTTCCAACAGCACCGTCTTATC-3' \\
\hline MIRU10R & 5'-TCGCACCGATCACGCTACG-3' \\
\hline MIRU16U & 5'-GTTGGAAACGGCGGTTATTGAC-3' \\
\hline MIRU16R & 5'-CGGAGTCGTCCAGCAAGACC-3' \\
\hline MIRU20U & 5'-TCGGAGAGATGCCCTTCGAGTTAG -3' \\
\hline MIRU20R & 5'-TCACGGTCTCCGCACTAACG-3' \\
\hline MIRU23U & 5'-CTCACCAGGATCGCCAAACC-3' \\
\hline MIRU23R & 5'-TCTGACTCATGGTGTCCAACC-3' \\
\hline MIRU24U & 5'-GCTTGTGCGGGAAGGCTA-3' \\
\hline MIRU24R & 5'-CGATCGCGGATCTTTGCT-3' \\
\hline MIRU26U & 5'-CCAGCAGTTGAGCACAGTTCG-3' \\
\hline MIRU26R & 5'-GGATAGGTCCGAGTTCGATTTCC-3' \\
\hline MIRU27U & 5'-CGGTGACCAACGTCAGATTC-3' \\
\hline MIRU27R & 5'-GCGATGTGAGCGTGCCACTCAA-3' \\
\hline MIRU31U & 5'-CTTCGGCGTCGAAGAGAGCCTC-3' \\
\hline MIRU31R & 5'-CGGAACGCTGGTCACCACCTAAG-3' \\
\hline MIRU39U & 5'-CATCGACAAACTGGAGCCAAAC-3' \\
\hline MIRU39R & 5'-GAAACGTCTACGCCCCACAC-3' \\
\hline MIRU40U & $5^{\prime}-$ GCAAGAGCAAGAGCACCAAGC-3' \\
\hline MIRU40R & 5'-TGTCTAATCAGGTCTTTCTCTCACGC-3' \\
\hline MTUB30U & 5'-CTTGAAGCCCCGGTCTCATCTGT-3' \\
\hline MTUB30R & 5'-ACTTGAACCCCCACGCCCATTAGTA-3' \\
\hline MTUB39U & 5'-CGGTGGAGGCGATGAACGTCTTC -3' \\
\hline MTUB39R & 5'-TAGAGCGGCACGGGGGAAAGCTTAG-3' \\
\hline QUB4156U & 5'-TGACCACGGATTGCTCTAGT-3' \\
\hline QUB4156R & 5'-GCCGGCGTCCATGTT-3' \\
\hline V11U & 5'- CGCTAGACGTCAGATCCCAG -3' \\
\hline V11R & 5'- GTCTGTTCCGACGCCAATAG -3' \\
\hline RD105U & 5'-GCTGTTTTGCTGTGGATTGTG-3' \\
\hline RD105R & 5'-TCACGTAGCCGCTCAAGAG-3' \\
\hline RD207U & 5'-GAGGATCTTCAGCAGTTGTTCTGG-3' \\
\hline RD207R & 5'-CTTGAAGTACTCGGAAGGTTCG-3' \\
\hline RD150-1 & 5'-GTGCTTCGGGGATCAAGG-3' \\
\hline RD150-2 & 5'-GGTCTATCCGCTATGTTGTGG-3' \\
\hline
\end{tabular}

Table 1 Oligonucleotide primers (Continued)

\begin{tabular}{lc}
\hline RD181-1 & 5'-CTGCCGCACAACCAATG-3' \\
RD181-2 & 5'-GTGGCGACCAGATCCTTG-3' \\
RD150-4 & 5'-GTGCTTCGGGGATCAAGG-3' \\
RD150-3 & 5'-GGTCTATCCGCTATGTTGTGG-3' \\
RD142-U & 5'-CGAGTCAAGGCGATGTTC-3' \\
RD142-R & 5'-GATGTGGTCGTGGTCTCC-3' \\
RD149-1 & 5'-GTAGAGGGTTCCAGTTCCAG-3' \\
RD149-2 & 5'-GACGCCGTTGACTTGTTG -3' \\
RD152-3 & 5'-GCAGCAACCACCAGGACTC-3' \\
RD152-4 & 5'-ACATCAACGCAGCCATCG-3' \\
RD174-U & 5'-CAAGAATCCAAGGCAGAG-3' \\
RD174-R & 5'-CTAACAGCACAAGGTCAC-3' \\
RD239-1 & 5'-GACCAACCCTGCTCTTCTAC-3' \\
RD239-2 & 5'-TTGGCGAGGTCTCTTGTC-3' \\
RD702-U & 5'-GGTGGGTGATGTCGGATTGG-3' \\
RD702-R & 5'-CAGGCGGTCGGTGAATGC-3' \\
RD711-U & 5'-TATCCCGATGACCAATGC-3' \\
RD711-R & 5'-TGCGAGTGATAGATGACG-3' \\
RD724-U & 5'-TCGTAGGGATGACTTGAC-3' \\
RD724-R & 5'-AAGCGTGTAAAGAGGAAC-3' \\
RD750-1 & 5'-CTCATAGATCACTCGCACAGG-3' \\
RD750-2 &
\end{tabular}

elongation at $72^{\circ} \mathrm{C}$ for $20 \mathrm{~s}$, with a final elongation step at $72^{\circ} \mathrm{C}$ for $3 \mathrm{~min}$. The presence of an amplification product was verified by $6 \%$ PAGE with subsequent visualization of the DNA by ethidium bromide staining. PCR products were sequenced in SB RAS Genomics Core Facility according to the manufacturer's instructions using a Big Dye Terminator v3.1 Cycle Sequencing Kit (Life Technologies Corp., Carlsbad, CA) with the same primers used for PCR and run on an ABI PRISM 3130xl Genetic Analyzer (Life Technologies.). Mutations were detected in the genes by comparison with the $M$. tuberculosis wild-type reference laboratory strain (H37Rv) using Unipro UGENE software (version 1.11.3) (http://ugene.unipro.ru/).

\section{VNTR-typing}

VNTR typing of ETR-A, ETR-B, ETR-C, MIRU 2, MIRU4, MIRU10, MIRU16, MIRU20, MIRU23, MIRU24, MIRU26, MIRU27, MIRU31, MIRU39, MIRU40, Mtub30, Mtub39, QUB4156, and V11 loci was performed by PCR in a volume of $20 \mu \mathrm{l}$ containing $65 \mathrm{mM}$ Tris- $\mathrm{HCl}(\mathrm{pH} 8.9)$, $23 \mathrm{mM}$ (NH4)2SO4, $3 \mathrm{mM} \mathrm{MgCl} 2,0.05 \%$ Tween 20, $0.2 \mathrm{mM}$ dNTPs, $1 \mu \mathrm{M}$ loci-specific oligonucleotide primers, $1 \mathrm{U}$ Taq DNA polymerase and 1-10 ng of $M$. tuberculosis genomic DNA, as described previously $[7,8]$. The oligonucleotide primer sequences are shown in Table 1. Reactions were carried out in an iCycler amplifier 
(Bio-Rad, California, USA) where, after an initial denaturation step of $96^{\circ} \mathrm{C}$ for $3 \mathrm{~min}, 38$ cycles were performed as follows: denaturation at $95^{\circ} \mathrm{C}$ for $10 \mathrm{~s}$, annealing at $60^{\circ} \mathrm{C}$ for $10 \mathrm{~s}$, elongation at $72^{\circ} \mathrm{C}$ for $30 \mathrm{~s}$, and a final elongation at $72^{\circ} \mathrm{C}$ for $3 \mathrm{~min}$. The presence of an amplification product was checked by $6 \%$ PAGE with subsequent visualization of the DNA by ethidium bromide staining. The number of tandem repeat copies was calculated as a function of the size of the PCR product. The structure and number of repeat copies was also verified selectively by direct sequencing of the amplified DNA fragments. The genotype of each isolate was expressed as a set of 19 digits where each digit showed the number of copies of the corresponding tandem repeat.

\section{Deligotyping}

Deligotyping was performed as described previously $[9,10]$. Typing was performed by real-time PCR in a $20 \mu \mathrm{l}$ volume containing $10 \mathrm{mM}$ Tris- $\mathrm{HCl}(\mathrm{pH} 8.9)$, $2.5 \mathrm{mM} \mathrm{MgCl}_{2}, 0.2 \mathrm{mM}$ dNTPs, $55 \mathrm{mM} \mathrm{KCl}, 0.05 \%$ Tween 20, $1 \mathrm{U}$ Taq DNA polymerase, and 1-10 ng $M$. tuberculosis genomic DNA. SybrGreen I (supplied as a $10000 \times$ solution; Life Technologies), was used at a final concentration of $0.2 \times$. The oligonucleotide primer sequences are given in Table 1. Reactions were carried out in an iCycler iQ5 (Bio-Rad) with initial denaturation step of $96^{\circ} \mathrm{C}$ for $3 \mathrm{~min}$, followed by 40 cycles of denaturation at $96^{\circ} \mathrm{C}$ for $10 \mathrm{~s}$, annealing at $62^{\circ} \mathrm{C}$ for $20 \mathrm{~s}$, and elongation at $72^{\circ} \mathrm{C}$ for $10 \mathrm{~s}$, with data acquisition at $72^{\circ} \mathrm{C}$ on the SYBR channel (excitation at $470 \mathrm{~nm}$; detection at $585 \mathrm{~nm}$ using a high pass filter) and melting curves for the amplified products from $82^{\circ} \mathrm{C}$ to $96^{\circ} \mathrm{C}$ (in $0.2^{\circ} \mathrm{C}$ increment).

\section{Statistical analysis}

Statistical data processing was performed using STATISTICA 6.0 (StatSoft, www.statsoft.com). Cluster analysis and dendrogram construction were performed using UPGMA and the neighbor-joining method. To determine the congruence of the two methods, the Rand coefficient was used [11]. The cut-off for significance was taken as $\mathrm{P}<0.05$. The minimum spanning tree (MST) was built using the eBurst algorithm [12]. The Hunter-Gaston Discrimination Index (HGDI) was used as an estimate of the allelic diversity for specific areas in the 19 combined loci [13].

\section{Results}

\section{Sample description}

In our dataset, the patients were aged 20 to 61 (mean $34.9 \pm 10.9$ ), with males comprising 58.6\%. In Table 2, we introduced artificially age ranges: the minimum value plus one, two and so on standard deviations, obtain several age ranges (20-30,9 (I); 30.9 - 41.8 (II); 41.8 - 52.7 (III); 52,7 63, 6 (IV)). Six patients had primary tuberculosis; the others had chronic tuberculosis, where a reinfection or reactivation had occurred. Isolates 133 and 236 were obtained from one patient. Regarding the diagnosis of tuberculosis, patients were divided as follows: fibrocavernous tuberculosis (17), infiltrative tuberculosis (7), disseminated tuberculosis (3), and caseous pneumonia (2). Only six patients had no comorbidities. Some patients had two or more diseases; for example, hepatitis $\mathrm{C}$ was detected among 10 patients (among them one patient had hepatitis B, while two had HIV), bronchitis affected nine patients, different diseases of the gastrointestinal tract affected eight patients, diabetes affected one. Five patients were connected with penitentiary systems, 12 patients had earlier contact with TB patients, of whom eight had family contact. Tuberculosis was diagnosed in 20 patients treated by the general health services, whereas nine cases were obtained from preventive examinations (Table 2).

Only five patients had no complaints at the time of admission to the NRIT (isolates 78 and 285). The other patients complained of cough, shortness of breath, fever, and weight loss. Lesions in the lungs, from single to multiple, and from small to giant size, were detected radiographically. The disintegration of lung-tissues was not detected in one case, but the progression of tuberculosis disease was repeatedly observed in the form of increasing infiltration size (isolate 37). All patients had smear-positive tuberculosis. All cases with identified isolates of the M. tuberculosis Latino-American Mediterranean (LAM) family (isolates 15 and 48) were characterized by unfavorable epidemiological histories: one patient was infected in prison, while the second patient worked three years as a nurse in a morgue and was involved in autopsies.

\section{Drug-susceptibility patterns}

Using conventional methods, it was shown that all 30 isolates were multidrug-resistant TB (MDR-TB, i.e. resistant to at least isoniazid and rifampicin); of these, 29 $(96,6 \%)$ were characterized as extensively drug-resistant, while $10(33 \%)$ were resistant to all of the drugs that were tested.

\section{Mutations identified in the rpoB, katG, rrs, tlyA, gidB, rpsL, gyrA, gyrB, and pncA genes}

Mutations in the rpoB, katG, rrs, tlyA, gidB, rpsL, gyrA, $g y r B$, and $p n c A$ genes were used as markers of the drug resistance phenotypes in the isolates. Sequence analysis of selected isolates of $M$. tuberculosis identified the mutations shown in Table 3.

The presence of a mutation in codon 531 of the rpoB gene, which encodes the $\beta$-subunit of RNA polymerase and is involved in rifampicin resistance, was found in 27 of the 30 isolates (90\%). In particular, among 12 isolates it was the only mutation present in this gene, while the other 14 isolates harbored S531L and S540R mutations. 
Table 2 Initial data on the investigated 30 clinical isolates M.tuberculosis observed among 29 tuberculosis patients

\begin{tabular}{|c|c|c|c|c|c|c|c|c|c|c|c|c|c|c|c|c|c|c|}
\hline № & Region & S & $\mathrm{H}$ & Et & E & $\mathrm{Cp}$ & A & $\mathrm{K}$ & $\mathbf{R}$ & Of & $z$ & $\begin{array}{l}\text { Duration } \\
\text { of illness }\end{array}$ & $\begin{array}{c}\text { Age } \\
\text { ranges }\end{array}$ & Sex & DS & Comorbidities & Epidemic history & Complaints \\
\hline 6 & 2 & 1 & 1 & 1 & 1 & 1 & 1 & 1 & 1 & 1 & 1 & 2 & 1 & f & FCPT & No & Family & Cough \\
\hline 9 & 1 & 1 & 1 & 0 & 0 & 1 & 1 & 1 & 1 & 1 & 1 & 2 & III & $\mathrm{m}$ & FCPT & No & Prison & Cough, shortness of breath \\
\hline 15 & 3 & 1 & 1 & 1 & 1 & 1 & 1 & 1 & 1 & 1 & 1 & 2 & $\|$ & $\mathrm{m}$ & FCPT & HCV, drug addiction & Prison & $\begin{array}{l}\text { Cough, shortness of breath, } \\
\text { fever, }\end{array}$ \\
\hline 17 & 2 & 1 & 1 & 1 & 1 & 0 & 0 & 1 & 1 & 1 & 1 & 2 & I & $f$ & FCPT & Chronic bronchitis & Family & Cough, hemoptysis \\
\hline 20 & 4 & 1 & 1 & 1 & 0 & 0 & 1 & 0 & 1 & 0 & 1 & 2 & $\|$ & $f$ & IPT & No & $\begin{array}{l}\text { Professional } \\
\text { (the nurse) }\end{array}$ & Cough \\
\hline 21 & 3 & 1 & 1 & 0 & 1 & 1 & 1 & 1 & 1 & 1 & 1 & 1 & । & $\mathrm{m}$ & IPT & Chronic gastritis & No & $\begin{array}{l}\text { Weakness, sweating, fever, } \\
\text { hemoptysis }\end{array}$ \\
\hline 37 & 3 & 1 & 1 & 1 & 0 & 0 & 1 & 1 & 1 & 1 & 1 & 2 & $\|$ & $f$ & IPT & $\begin{array}{c}\text { Neurocirculatory dystonia, encephalopathy, cervical } \\
\text { osteochondrosis, cervicalgia, cyst of the right lobe of the } \\
\text { liver }\end{array}$ & $\begin{array}{l}\text { Professional } \\
\text { (the physiacion) }\end{array}$ & Shortness of breath \\
\hline 38 & 9 & 1 & 1 & 1 & 1 & 0 & 0 & 1 & 1 & 1 & 1 & 2 & । & $f$ & DPT & No & Family & Shortness of breath, weakness \\
\hline 48 & 10 & 1 & 1 & 1 & 1 & 1 & 1 & 1 & 1 & 1 & 1 & 2 & $\|$ & m & DPT & Peptic ulcer, chronic cholecystitis, HCV, HBV & $\begin{array}{l}\text { Family/professional } \\
\text { (corpsman in the } \\
\text { morgue) }\end{array}$ & Cough \\
\hline 78 & 3 & 1 & 1 & 1 & 1 & 1 & 0 & 0 & 1 & 1 & 1 & 2 & $\|$ & $f$ & FCPT & $\mathrm{HCV}$ & Family & No \\
\hline 87 & 3 & 1 & 1 & 0 & 0 & 0 & 0 & 1 & 1 & 1 & 0 & 1 & । & f & FCPT & Bronchitis after postural drainage & Family & Shortness of breath \\
\hline 94 & 5 & 1 & 1 & 1 & 1 & 1 & 1 & 1 & 1 & 1 & 1 & 2 & $\|$ & f & FCPT & Obstructive bronchitis, bronchial asthma, syphilis & No & $\begin{array}{c}\text { Cough, weakness, shortness of } \\
\text { breath }\end{array}$ \\
\hline 96 & 4 & 1 & 1 & 1 & 1 & 1 & 0 & 0 & 1 & 1 & 1 & 2 & । & f & FCPT & $\mathrm{HCV}$ & Family & Weaknwss, chest pain \\
\hline 128 & 6 & 1 & 1 & 1 & 0 & 1 & 1 & 1 & 1 & 1 & 1 & 2 & । & $\mathrm{m}$ & FCPT & Duodenal ulcer & No & Cough \\
\hline 133 & 7 & 1 & 1 & 1 & 0 & 0 & 1 & 1 & 1 & 1 & 1 & 2 & $\|$ & $\mathrm{m}$ & FCPT & Chronic pancreatitis & No & Cough \\
\hline 145 & 3 & 1 & 1 & 0 & 1 & 1 & 1 & 1 & 1 & 1 & 0 & 2 & $\|$ & $\mathrm{m}$ & IPT & HCV, drug addiction & Prison (1998-2001) & Cough \\
\hline 158 & 3 & 1 & 1 & 1 & 1 & 1 & 1 & 1 & 1 & 1 & 0 & 1 & । & $\mathrm{m}$ & IPT & No & No & $\begin{array}{l}\text { Cough, shortness of breath, } \\
\text { sweating }\end{array}$ \\
\hline 169 & 6 & 1 & 1 & 1 & 1 & 0 & 1 & 1 & 1 & 1 & 1 & 2 & । & $f$ & FCPT & Respiratory failure 1 level, chronic adnexitis & No & Cough, fever, hemoptysis \\
\hline 171 & 3 & 1 & 1 & 1 & 1 & 0 & 0 & 0 & 1 & 1 & 1 & 2 & । & $\mathrm{m}$ & FCPT & $\begin{array}{c}\text { Secondary bronchial obstruction, respiratory failure } 2 \text {, } \\
\text { heart failure, cachexia }\end{array}$ & No & $\begin{array}{l}\text { Cough, shortness of breath, } \\
\text { weakness, chest pain, weight } \\
\text { loss }\end{array}$ \\
\hline 235 & 3 & 1 & 1 & 1 & 1 & 1 & 0 & 1 & 1 & 1 & 1 & 1 & IV & $\mathrm{m}$ & $\mathrm{CP}$ & $\begin{array}{c}\text { Diabetes, steatohepatitis, chronic cholecystitis, } \\
\text { cholelithiasis }\end{array}$ & No & $\begin{array}{l}\text { Cough, shortness of breath, } \\
\text { weakness }\end{array}$ \\
\hline 236 & 7 & 1 & 1 & 1 & 1 & 1 & 1 & 1 & 1 & 1 & 1 & 2 & $\|$ & m & FCPT & Chronic pancreatitis & No & Cough \\
\hline 238 & 3 & 1 & 1 & 1 & 1 & 1 & 1 & 1 & 1 & 1 & 1 & 2 & IV & m & FCPT & Obstructive bronchitis, emphysema, heart failure & No & Shortness of breath \\
\hline 275 & 8 & 1 & 1 & 1 & 1 & 1 & 1 & 1 & 1 & 1 & 1 & 1 & । & f & FCPT & HCV, bronchitis & $\begin{array}{l}\text { Contact with } \\
\text { neighbors }\end{array}$ & $\begin{array}{c}\text { Cough, weakness, shortness of } \\
\text { breath }\end{array}$ \\
\hline 276 & 3 & 1 & 1 & 1 & 1 & 1 & 1 & 1 & 1 & 1 & 0 & 1 & IV & $\mathrm{m}$ & DPT & Gastrectomy, HCV, respiratory failure, cachexia & No & Cough, weight less \\
\hline
\end{tabular}


Table 2 Initial data on the investigated 30 clinical isolates M.tuberculosis observed among 29 tuberculosis patients (Continued)

\begin{tabular}{|c|c|c|c|c|c|c|c|c|c|c|c|c|c|c|c|c|c|}
\hline 285 & 8 & 1 & 1 & 1 & 11 & 11 & 11 & 1 & 1 & 1 & 2 & $\|$ & $\mathrm{m}$ & FCPT & $\mathrm{HCV}$ & Prison (2007-2009) & No \\
\hline 287 & 3 & 1 & 1 & 1 & 11 & 11 & 11 & 1 & 1 & 1 & 2 & $\|$ & $\mathrm{m}$ & IPT & HIV, HCV, sinusitis, stomatitis, drug addiction & No & $\begin{array}{l}\text { Cough, shortness of breath, } \\
\text { weakness, sweating }\end{array}$ \\
\hline 300 & 11 & 1 & 1 & 0 & 0 & 11 & 11 & 1 & 1 & 0 & 2 & $\|$ & $\mathrm{m}$ & FCPT & Obstructive bronchitis & Prison & Cough, fever, chest pain \\
\hline 309 & 3 & 1 & 1 & 1 & 1 & 10 & 01 & 1 & 1 & 1 & 2 & $\|$ & $\mathrm{m}$ & IPT & HIV, HCV, drug addiction & $\begin{array}{l}\text { Contact with } \\
\text { neighbors }\end{array}$ & Cough with sputum \\
\hline 1084 & 8 & 1 & 1 & 1 & 11 & 11 & 11 & 1 & 1 & 1 & 2 & । & m & $\mathrm{CP}$ & Obstructive bronchitis & Family & Cough, chest pain \\
\hline 4548 & 3 & 1 & 1 & 1 & 10 & $0 \quad 1$ & 11 & 1 & 1 & 1 & 2 & IV & f & FCPT & Obstructive bronchitis, hypertonic disease ॥ & Death & Shortness of breath, tirednes \\
\hline
\end{tabular}

Note: In the column 'region' numbers denote: 1 - Jewish Autonomous Oblast, 2 - the Krasnoyarsk Kray, 3 - Novosibirsk region, 4 - Omsk Oblast, 5 - Chita city, 6 - Kemerovo oblast, 7 - Kamchatka, 8 - The Republic of Khakassia, 9 - The Tuva Republic, 10 - Tomsk, 11 - Altay Republic. Resistance to anti-TB drugs: 1 - resistant, 0 - sensitive. Designation column: S - streptomycin, H - isoniazid, Et - ethionamide, E - ethambutol, CAP - capreomycin, A - amikacin, K-kanamycin, R - rifampicin, Of - ofloxacin, Z - pyrazinamide. In the column “ duration of illness": 1 - primary tuberculosis, 2 - secondary tuberculosis. In the column «DS» - diagnosis: FCPT - Fibrous-cavernous pulmonary tuberculosis, DPT - disseminated pulmonary tuberculosis, IPT - infiltrative pulmonary tuberculosis, CP - cheesy pneumonia. * - the isolates from one patient. 
Table 3 Mutations in rpoB, katG, gidB, pncA, gyrA, gyrB, rpsL, rrs, and tlyA genes associated with the formation of drug resistance and the following amino acid substitutions

\begin{tabular}{|c|c|c|c|c|c|c|c|c|c|}
\hline № & rpoB & katG & gidB & pncA & gyr A & gyrB & rpsL & rrs & tlyA \\
\hline 6 & S531L, S540R & S315T & E92D & $A-11 G$ & S95T & No mutation & K43R & $1401 \mathrm{~A} \rightarrow \mathrm{G}$ & $\overline{\mathrm{L} 11 \mathrm{~L}}$ \\
\hline 9 & S531L, S540R & S315T & E92D & 15T & D94A, S95T & No mutation & K43R & 1401 A $\rightarrow$ G, DelA 1473396 & L11L \\
\hline 15 & S531L, S540R & S315T & L10R & $\mathrm{T}-7 \mathrm{C}$ & D94N, S95T & No mutation & No mutation & $1401 A \rightarrow G, 685 G \rightarrow A$ & L11L \\
\hline 17 & S531L, S540R & S315T & E92D & $48 \mathrm{Ins} G$ & D94H, S95T & No mutation & K43R & No mutation & L11L \\
\hline 20 & L511P, D516G, S540R & S315T & E92D & L4W & S95T & No mutation & No mutation & No mutation & L11L \\
\hline 21 & S531L, S540R & S315T & E92D & Y99STOP & A90V, S95T & No mutation & K43R & $1401 \mathrm{~A} \rightarrow \mathrm{G}$ & L11L \\
\hline 37 & S531L, S540R & S315T & E92D & T76P & D94A, S95T & No mutation & K43R & No mutation & L11L \\
\hline 38 & S531L, S540R & S315T & E92D & L120P & D94E, S95T & No mutation & K43R & $1401 \mathrm{~A} \rightarrow \mathrm{G}$ & L11L \\
\hline 48 & D516V, S540R & $\mathrm{S} 315 \mathrm{~T}$ & L10R & $\mathrm{T} 76 \mathrm{P}$ & A90V, S95T & No mutation & No mutation & $1401 \mathrm{~A} \rightarrow \mathrm{G}$ & N/A \\
\hline 78 & S531L, S540R & S315T & E92D & $A 28 D$ & D94G, S95T & No mutation & K43R & No mutation & N/A \\
\hline 87 & S531L, S540R & S315T & E92D & D12A & D94G, S95T & No mutation & K43R & No mutation & N/A \\
\hline 94 & S531L & S315T & E92D & V139A & S91P, S95T & No mutation & K43R & $1401 \mathrm{~A} \rightarrow \mathrm{G}$ & N/A \\
\hline 96 & H513L & S315T & N/A & No mutation & D94N, S95T & No mutation & No mutation & No mutation & N/A \\
\hline 128 & S531L & S315T & E92D & Del G pos256, S179V & N/A & No mutation & K88R & $1401 \mathrm{~A} \rightarrow \mathrm{G}$ & L11L \\
\hline $133^{*}$ & S531L & S315T & E92D & N/A & D94G, S95T & No mutation & K43R & $1401 \mathrm{~A} \rightarrow \mathrm{G}$ & N/A \\
\hline 145 & L533P, S540R & S315T & E92D & Del C pos 428 & D94G, S95T & No mutation & K43R & No mutation & L11L \\
\hline 158 & S531L & S315T & E92D & No mutation & S95T & No mutation & K43R & $1401 \mathrm{~A} \rightarrow \mathrm{G}$ & N/A \\
\hline 169 & S531L, S540R & S315T & E92D & $A-11 G$ & D94Y, S95T & No mutation & K43R & No mutation & L11L \\
\hline 171 & S531L & S315T & E92D & No mutation & S95T & No mutation & K43R & No mutation & L11L \\
\hline 235 & S531L & S315T & E92D & V7G & A90V, S95T & No mutation & K43R & No mutation & L11L \\
\hline $236^{*}$ & S531L, S540R & S315T & E92D & N/A & D94G, S95T & No mutation & K43R & $1401 \mathrm{~A} \rightarrow \mathrm{G}$ & L11L \\
\hline 238 & S531L & S315T & I81I, E92D & V45G, I31S & D94G, S95T & No mutation & K43R & $1401 \mathrm{~A} \rightarrow \mathrm{G}$ & L11L \\
\hline 275 & S531L & $\mathrm{S} 315 \mathrm{~T}$ & E92D & No mutation & D94A, S95T & No mutation & K43R & $1401 \mathrm{~A} \rightarrow \mathrm{G}$ & L11L \\
\hline 276 & S531L & S315T & N/A & No mutation & S95T & No mutation & No mutation & $1401 \mathrm{~A} \rightarrow \mathrm{G}$ & N/A \\
\hline 285 & S531L & S315T & E92D & L172P & D94A, S95T & No mutation & K43R & $1401 \mathrm{~A} \rightarrow \mathrm{G}$ & L11L \\
\hline 287 & S531L & S315T & N/A & 1315 & S91P, S95T & No mutation & K43R & $1401 \mathrm{~A} \rightarrow \mathrm{G}$ & N/A \\
\hline 300 & S531L, S540R & S315T & E92D, R102P & 1315 & A90V, S95T & No mutation & K43R & $1401 \mathrm{~A} \rightarrow \mathrm{G}$ & N/A \\
\hline 309 & S531L, S540R & S315T & N/A & A146T & A90V, S95T & No mutation & K43R & $1401 \mathrm{~A} \rightarrow \mathrm{G}$ & N/A \\
\hline 1084 & S531L, S540R & S315T & N/A & D8N & D94N, S95T & No mutation & K43R & $1401 \mathrm{~A} \rightarrow \mathrm{G}$ & N/A \\
\hline 4548 & S531L & S315T & E92D & Del A pos 353 & D94G, S95T & No mutation & K43R & $1401 \mathrm{~A} \rightarrow \mathrm{G}$ & N/A \\
\hline
\end{tabular}


In three cases it was found that isolate 145 contained the mutation in codons L533P and S540R, whereas isolate 48 contained D516V and S540R. In addition, isolate 96 had the H513L substitution in the RpoB protein.

The kat $G$ gene is involved in the formation of isoniazid resistance. Sequencing of a fragment of this gene revealed the presence of a mutation resulting in a S315T substitution in all the DNA samples from the M. tuberculosis isolates (Table 3).

The rrs gene, encoding $16 \mathrm{~S}$ ribosomal RNA, is involved in resistance to amikacin, kanamycin and capreomycin. Among the 30 isolates, 20 had the same nucleotide change at position $1401(\mathrm{~A} \rightarrow \mathrm{G})$, while a $\mathrm{G} \rightarrow \mathrm{A}$ substitution at position 685 was identified in one isolate (no. 15). Additional mutations (Table 3, delA) were found in the intergenic region (between the rrs genes (RVBD 6066) encoding 16S rRNA, and RV6067, encoding 23S rRNA) in the nucleotide position 1473396v (no. 9). Ten isolates did not contain any mutations in rrs. The tlyA gene, which encodes hemolysin, is also responsible for resistance to amikacin, kanamycin and capreomycin. Analysis of sequenced fragments of this gene showed the presence of synonymous mutations (CTA33CTG, L11L) in several samples (Table 3).

The gidB gene, encoding the ribosomal RNA small subunit methyltransferase $G$, is responsible for resistance to streptomycin. In 23 of the sequenced samples, a mutation (A276C) in gidB that results in a nonsynonymous (E92D) change in its protein product was identified; one isolate contained the substitution R102P (no. 300), while another contained a synonymous mutation (I81I) in GidB. Two isolates contained the L10R substitution. In five cases we were unable to amplify the gidB gene fragment (Table 3).

In contrast, we found that the $p n c A$ gene, which encodes pyrazinamidase, exhibited a much higher diversity level in the range of nonsynonymous mutations and sequence deletions, and only five samples did not harbor mutations in this gene (Table 3).

The gyrA gene, which codes for the DNA gyrase subunit $\mathrm{A}$, is involved in ofloxacin resistance. In most cases nonsynonymous mutations were found in the 90th, 94th, and 95th codons of this gene. In one case we were unable to amplify this gene (no 128). In the gyrB gene, which encodes the DNA gyrase subunit B, no mutations were detected.

The rpsL gene, which encodes the ribosomal protein S12, is responsible for streptomycin resistance. In 24 cases $(80 \%)$ a mutation leading to the amino acid substitution K43R was detected. In five cases no mutations were detected (Table 3).

Taking into account the results of the antibiotic susceptibility testing (Table 2) and genotypic determination of the mutations described above (Table 3), the status of extensively drug-resistance (XDR TB) has been assigned to 29 of the isolates. In addition, isolate 20 had the mutation in the gyrA gene that leads to ofloxacin resistance.

\section{Deligotyping}

For deligotyping we used the following loci: RD105, RD149, RD152, RD174, RD181, RD207, RD150, RD239, RD702, RD711, RD724, and RD750, as described by Tsolaki et al. [14]. Oligonucleotide primers were synthesized so that the presence of the amplification product indicated the absence of the deletion in the variable region [10]. Using this technique, we found that 28 of the $30 \mathrm{M}$. tuberculosis clinical isolates did not contain RD105, RD149, RD152, RD181, and RD207 loci in their genomes, thus confirming that they belonged to the Beijing family (Table 4). The presence of RD105, RD181, and RD207 in two of the DNA samples indicated that these isolates belonged to other $M$. tuberculosis families; this was further confirmed by VNTR typing, which showed that these isolates belonged to the LAM family.

RD149 and RD152 loci were absent in all the 30 mycobacterial DNA samples analyzed. However, RD150, RD239, RD702, RD711 and RD724 loci were found in all of the DNA samples The Hunter-Gaston discrimination index (HGDI) for deligotyping was equal to 0.128 .

\section{VNTR-typing}

$M$. tuberculosis genetic families were determined using VNTR typing and the MIRU-VNTRplus database (http:// www.miru-vntrplus.org/MIRU/index.faces) [15]. We hypothesized that most of the $M$. tuberculosis isolates characterized as having extensive drug resistance would belong to the Beijing family. Hence, we used the 15 standard VNTR-loci proposed by Supply et al. for genotyping [16]. For enhanced differentiation we used four additional loci (Mtub30, Mtub39, Qub4156, V11) for closely related isolates of the Beijing family, which proved to be highly discriminatory [17]. It was shown that among the 30 clinical isolates, 28 belonged to the Beijing family (Table 4). Using the classification of Mokrousov [18], we identified 28 isolate types of the Beijing family: 11 isolates (39.3\%) belonged to the M11 type, 2 (7.1\%) were the M2 type, while one isolate (3.6\%) was the M33 type. The remaining 14 isolates $(50.0 \%)$ could not be attributed to any known type based on this classification method; hence, they have been labeled 'unknown'. For each locus, the HGDI and its associated confidence intervals was calculated (Table 5). Additionally, the total HGDI for VNTR-typing was calculated as 0.889 .

\section{Cluster analysis by VNTR}

To elucidate the phylogenetic relationships between the M. tuberculosis isolates we constructed a MST based on VNTR-sections (Figure 1). This tree is a branched chain 
Table 4 VNTR-typing and deligotyping results for $30 \mathrm{M}$. tuberculosis isolates

\begin{tabular}{|c|c|c|c|c|}
\hline No & Beijing type & RD-profile & VNTR-profile & VNTR - type \\
\hline 15 & - & $1,0,0,1,1,1,1,1,1,1,1,1$ & $2,2,2,3,2,1,4,3,2,5,1,6,3,2,5,1,4,10,3$ & 1 \\
\hline 48 & - & $1,0,0,1,1,1,1,1,1,1,1,1$ & $2,2,2,3,2,2,3,3,3,2,5,1,5,3,2,5,1,4,10,3$ & 2 \\
\hline 158 & Unknown & $0,0,0,1,0,0,1,1,1,1,1,1$ & $3,2,4,3,3,2,3,3,3,2,5,1,5,3,3,4,4,5,10,6$ & 3 \\
\hline 300 & Unknown & $0,0,0,1,0,0,1,1,1,1,1,1$ & $4,2,4,3,2,2,3,3,2,5,1,5,3,3,3,4,5,10,5$ & 4 \\
\hline 309 & Unknown & $0,0,0,1,0,0,1,1,1,1,1,1$ & $4,2,4,3,2,2,3,3,3,2,5,1,7,3,3,3,4,4,5,10,5$ & 5 \\
\hline 145 & Unknown & $0,0,0,1,0,0,1,1,1,1,1,1$ & $4,2,4,3,5,2,3,3,3,2,5,1,5,2,1,3,4,5,10,5$ & 6 \\
\hline 169 & Unknown & $0,0,0,1,0,0,1,1,1,1,1,1$ & $4,2,4,3,5,2,3,3,2,2,5,1,5,2,1,3,4,5,10,5$ & 6 \\
\hline 235 & Unknown & $0,0,0,1,0,0,1,1,1,1,1,1$ & $4,2,4,3,5,2,3,3,2,5,1,5,2,1,4,4,5,10,5$ & 7 \\
\hline 128 & Unknown & $0,0,0,1,0,0,1,1,1,1,1,1$ & $4,2,4,3,5,2,3,3,3,2,5,1,5,2,3,3,4,5,10,5$ & 8 \\
\hline 236 & Unknown & $0,0,0,1,0,0,1,1,1,1,1,1$ & $4,2,4,3,5,2,3,3,3,2,5,1,5,3,2,3,4,5,10,5$ & 9 \\
\hline 94 & M2 & $0,0,0,1,0,0,1,1,1,1,1,1$ & $4,2,4,3,5,2,3,3,3,2,5,1,5,3,3,3,3,4,5,10,5$ & 10 \\
\hline 133 & M2 & $0,0,0,1,0,0,1,1,1,1,1,1$ & $4,2,4,3,5,2,3,3,2,5,1,5,3,3,3,4,5,10,5$ & 10 \\
\hline 20 & M33 & $0,0,0,1,0,0,1,1,1,1,1,1$ & $4,2,4,3,5,2,3,3,3,2,5,1,6,3,3,3,3,4,5,10,5$ & 11 \\
\hline 87 & Unknown & $0,0,0,1,0,0,1,1,1,1,1,1$ & $4,2,4,3,5,2,3,3,2,5,1,1,7,1,1,3,4,5,10,5$ & 12 \\
\hline 275 & Unknown & $0,0,0,1,0,0,1,1,1,1,1,1$ & $4,2,4,3,5,2,3,3,2,5,1,7,2,1,3,4,5,10,5$ & 13 \\
\hline 238 & Unknown & $0,0,0,1,0,0,1,1,1,1,1,1$ & $4,2,4,3,5,2,3,3,2,2,5,1,7,3,1,3,4,5,10,5$ & 14 \\
\hline 285 & Unknown & $0,0,0,1,0,0,1,1,1,1,1,1$ & $4,2,4,3,5,2,3,3,3,2,5,1,7,3,1,3,4,5,10,5$ & 14 \\
\hline 6 & M11 & $0,0,0,1,0,0,1,1,1,1,1,1$ & $4,2,4,3,5,2,3,3,2,5,1,7,3,3,3,4,5,10,5$ & 15 \\
\hline 9 & M11 & $0,0,0,1,0,0,1,1,1,1,1,1$ & $4,2,4,3,5,2,3,3,2,2,5,1,7,3,3,3,3,4,5,10,5$ & 15 \\
\hline 17 & M11 & $0,0,0,1,0,0,1,1,1,1,1,1$ & $4,2,4,3,5,2,3,3,3,2,5,1,7,3,3,3,3,4,5,10,5$ & 15 \\
\hline 21 & M11 & $0,0,0,1,0,0,1,1,1,1,1,1$ & $4,2,4,3,5,2,3,3,2,2,5,1,7,3,3,3,3,4,5,10,5$ & 15 \\
\hline 37 & M11 & $0,0,0,1,0,0,1,1,1,1,1,1$ & $4,2,4,3,5,2,3,3,2,5,1,7,3,3,3,3,4,5,10,5$ & 15 \\
\hline 38 & M11 & $0,0,0,1,0,0,1,1,1,1,1,1$ & $4,2,4,3,5,2,3,3,2,5,1,7,3,3,3,3,4,5,10,5$ & 15 \\
\hline 78 & M11 & $0,0,0,1,0,0,1,1,1,1,1,1$ & $4,2,4,3,5,2,3,3,3,2,5,1,7,3,3,3,3,4,5,10,5$ & 15 \\
\hline 276 & M11 & $0,0,0,1,0,0,1,1,1,1,1,1$ & $4,2,4,3,5,2,3,3,2,2,5,1,7,3,3,3,3,4,5,10,5$ & 15 \\
\hline 287 & M11 & $0,0,0,1,0,0,1,1,1,1,1,1$ & $4,2,4,3,5,2,3,3,2,5,1,7,3,3,3,4,5,10,5$ & 15 \\
\hline 4548 & M11 & $0,0,0,1,0,0,1,1,1,1,1,1$ & $4,2,4,3,5,2,3,3,2,2,5,1,7,3,3,3,4,4,5,10,5$ & 15 \\
\hline 96 & Unknown & $0,0,0,1,0,0,1,1,1,1,1,1$ & $4,2,4,3,6,2,2,3,3,2,5,1,3,3,3,3,3,4,5,10,5$ & 16 \\
\hline 171 & Unknown & $0,0,0,1,0,0,1,1,1,1,1,1$ & $4,2,4,3,6,6,2,3,3,2,5,1,7,3,2,3,4,5,10,5$ & 17 \\
\hline 1084 & M11 & $0,0,0,1,0,0,1,1,1,1,1,1$ & $6,2,4,3,5,2,3,3,2,5,1,7,3,3,3,4,5,10,5$ & 18 \\
\hline
\end{tabular}

Note: Each number in the column "RD-profile" corresponds to the presence (1) or absence (0) of the region of differences (RD105, RD149, RD152, RD174, RD181, RD207, RD150, RD239, RD702, RD711, RD724, RD750) in the corresponding part of the genomic DNA sample. Similarly, in the column "VNTR-profile" each digit represents the number of repeats at a locus: ETRA, ETRB, ETRC, ETRD, ETRE, miru02, miru10, miru16, miru20, miru23, miru24, miru26, miru27, miru39, miru40, Mtub30, Mtub39, Qub4156, and V11.

wherein each vertex (a square with rounded corners) represents a VNTR-type (Table 4), and the square is specified by the number of types. Vertex size is directly proportional to the number of $M$. tuberculosis isolates with relevant VNTR-profiles. The tops of the tree branches are connected by edges, where the color denotes the difference between the two VNTR-types: black and blue represents a difference in one locus, green and dark gray represent differences in two different loci, and light gray represents differences in three loci. On the minimum spanning tree, we identified three clusters containing from three to six VNTR-types on the inside; these isolates differ from each other in a single copy at the locus analyzed. Three VNTR-types (nos. 1, 2, and 3, Table 4) had significantly different genetic profiles, and were not, therefore, included in the MST. VNTR-types 1 and 2 are consistent with $M$. tuberculosis DNA samples 15 and 48 that belong to the LAM family. VNTR-type 3 corresponds to sample 158, and is referred to by us as 'Beijing family group unknown'. Cluster I comprised the VNTRtypes 4, 8, 9, and 10, wherein the latter corresponds to the M2 type. Cluster II contains six VNTR-types $(5,11$, $15,16,17$, and 18): the most numerous of these (no. 15), consisted of 10 isolates of the M11 Beijing M. tuberculosis family. According to the scientific literature, the M2 type is dominant in Russia, but is also found in East 
Table 5 Hunter-Gaston diversity index with confidence intervals for each locus

\begin{tabular}{ccccc}
\hline Locus & Diversity index & Confidence interval & K & Max (pi) \\
\hline MIRU26 & 0.609 & $0.550-0.667$ & 5 & 0.548 \\
MIRU39 & 0.574 & $0.501-0.648$ & 4 & 0.613 \\
MIRU31 & 0.441 & $0.343-0.539$ & 5 & 0.742 \\
MIRU27 & 0.385 & $0.291-0.479$ & 4 & 0.774 \\
ETRA & 0.299 & $0.199-0.399$ & 5 & 0.839 \\
MIRU40 & 0.297 & $0.198-0.395$ & 4 & 0.839 \\
V11 & 0.243 & $0.148-0.338$ & 4 & 0.871 \\
MIRU10 & 0.187 & $0.099-0.275$ & 4 & 0.903 \\
MTUB30 & 0.185 & $0.099-0.271$ & 3 & 0.903 \\
ETRC & 0.185 & $0.099-0.271$ & 3 & 0.903 \\
MTUB39 & 0.185 & $0.099-0.271$ & 3 & 0.903 \\
MIRU2 & 0.127 & $0.051-0.203$ & 3 & 0.935 \\
MIRU16 & 0.065 & $0.008-0.121$ & 2 & 0.968 \\
MIRU20 & 0.065 & $0.008-0.121$ & 2 & 0.968 \\
MIRU24 & 0.065 & $0.008-0.121$ & 2 & 0.968 \\
MIRU23 & 0.065 & $0.008-0.121$ & 2 & 0.968 \\
ETRD & 0.065 & $0.008-0.121$ & 2 & 0.968 \\
QUB4156 & 0.065 & $0.008-0.121$ & 2 & 0.968 \\
ETRB & 0.065 & $0.008-0.121$ & 2 & 0.968 \\
\hline
\end{tabular}

Asia, albeit at a lower frequency [19]. Cluster III consists of three VNTR-types (nos. 12, 13, and 14), which are connected to two other types (nos. 6, and 7) at the level of one or two VNTR-loci changes, respectively. Although these VNTR-types (nos. 6, 7, 12, 13, and 14), as based on their characteristic VNTR-profiles, belong to the Beijing family, they did not have RD207 and RD105 regions of difference so we were unable to relate them to any of the known classification types described by Mokrousov [18].

\section{Discussion}

In this work, 30 isolates M. tuberculosis from 29 patients with TB were typed. One patient had a mixed population of $M$. tuberculosis genotypes. According to the scientific literature, in regions with high rates of TB morbidity and mortality, or in HIV-infected patients with tuberculosis, mixed populations of $M$. tuberculosis in humans might exist [20].

In this study, we used a traditional method, VNTRtyping, with 15 standard loci and 4 highly discriminatory loci for closely related strains, to analyze our isolates. Loci with the most discriminatory power were MIRU26, MIRU39, and MIRU31. What is unusual is that V11, Mtub30, Mtub39 and QUB4156 loci displayed relatively low Hunter-Gaston discrimination indices; this could be related to the distribution of certain genotypes in the $\mathrm{Si}$ berian and Far Eastern Federal Districts. The statistical analysis showed that the Rand index for the two typing methods was equal to 1 (i.e., the results of the deligotyping and VNTR-typing were consistent with each other). It should be noted that HGDI for the VNTR-typing was higher $(\mathrm{HGDI}=0.889)$ than the deligotyping (HGDI = 0.128 ) [13]. This may be caused by an enhanced rate of mutation in the variable tandem loci compared to regions of difference [21]. Despite the low HGDI, deligotyping is a quick and convenient method for molecularepidemiological prescreening of $M$. tuberculosis samples,

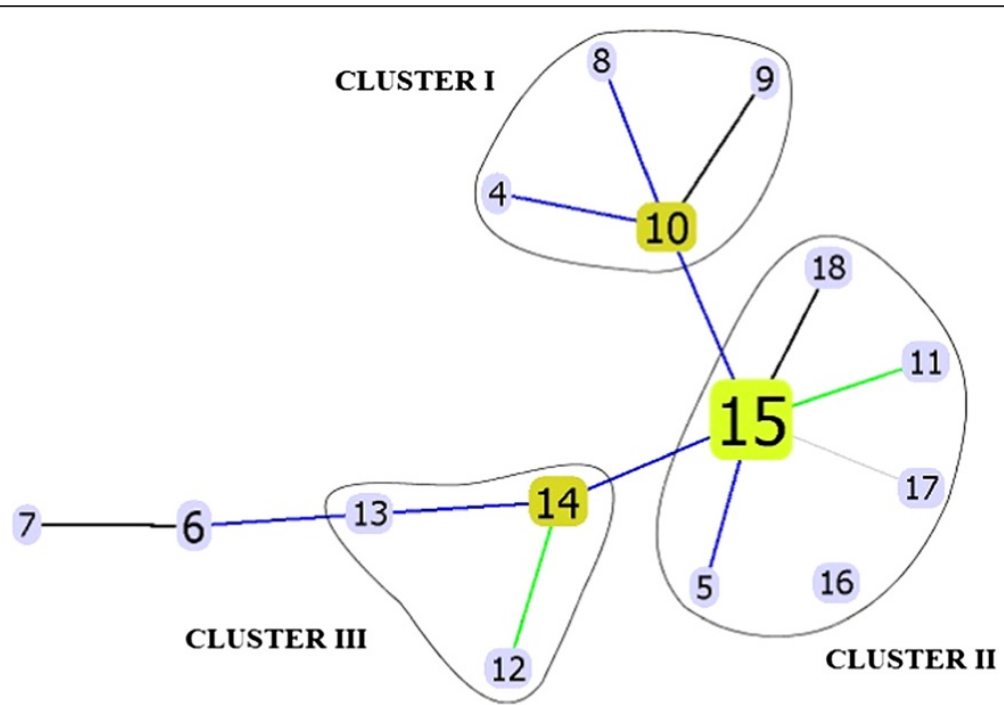

Figure 1 Minimum spanning tree based on VNTR-typing of $30 \mathrm{M}$.tuberculosis isolates using 19 polymorphic loci. Note: There are solid line circled clusters isolates (I, II, III) with similar the genetic profile. 
prior to more in-depth typing of mycobacteria by other methods.

Thus, in this study, among $30 \mathrm{M}$. tuberculosis isolates, of which 29 were characterized as XDR, 93.3\% belonged to Beijing family. We have previously shown that among isolates from patients with complicated forms of progressive pulmonary tuberculosis there is a predominance of isolates of this family (i.e., 84\% (37 of 44) [22]. In the present study, the frequency of Beijing family isolates from patients with severe forms of pulmonary tuberculosis in the city of Novosibirsk is significantly different from that in the general population (OR 7.1, 95\% CI [2.93-17.53], $\mathrm{P}<$ 0.0001). Our findings are consistent with those reported in other countries; for example, in Nepal, genotyping of XDR-TB isolates showed an overall prevalence of the Beijing family of $69 \%$ [23]. Taken together, the above data confirm that the Beijing family of $M$. tuberculosis is highly virulent in humans.

In the resulting minimal spanning tree, the VNTR-type 15, which corresponds to the M11 type, had the largest size, occupied a central position, which once again confirms its position in the ancestral population structure of the Beijing family [18]. We found that the distribution of the M11 type in our dataset was $36 \%$, while the M2 type was $6 \%$. Previously, several dominant isolate types of the Beijing family were identified that have epidemiological significance in the Russian Federation [24]. Five types are reported to occur at the greatest frequency, namely, M2, M8, M11, M28, and M33 [19]. M11 is the ancestral line that dominates Eurasia but is not found in Australia and South Africa. Isolates of this type have high adaptability and the ability to increase in numbers in THP-1 macrophages, as well as a high capacity to induce synthesis of the anti-inflammatory cytokine IL-10, and to induce macrophage necrosis. These biological characteristics in mycobacteria contribute to increased transmissibility and virulence, so identification of such strains using molecular genetic techniques will contribute to more effective use of drug therapy, and inform decisions on standard molecular epidemiological-related problems in TB. Identifying two isolates belonging to the LAM family is not surprising. This family is widespread and was found for the first time in Latin America, followed by the Mediterranean Basin [25]. In Russia, this family has the second highest incidence in the mycobacterial families after the Beijing type; these two families (LAM and Beijing) are associated with resistance to rifampicin and streptomycin [26]. Our spanning tree analysis showed that despite identical VNTR-profiles, isolates belonging to one cluster had different mutations in genes associated with the formation of drug resistance. For example, nine isolates belonging to MST No. 15 (Figure 1) have different mutations in pncA and $g y r A$ genes, primarily in pncA.

Another aspect of our work was focused on analyzing drug resistance in the $M$. tuberculosis clinical isolates.
The scientific literature refers to this type of isolate as pre-XDR-TB, or pre-totally drug-resistant-(TDR)-TB because the formation of resistance to additional drugs is a result of mutational events whereby such bacteria have become XDR and TDR, respectively. We searched for mutations in the genomes of the $M$. tuberculosis isolates that were associated with the formation of drug resistance using molecular genetics methods. It is known that the presence of non-synonymous mutations in the rrs gene causes resistance to streptomycin, amikacin, kanamycin, and capreomycin, whereas such substitutions in tlyA only confer resistance to amikacin, capreomycin and kanamycin. Resistance to streptomycin is conferred by non-synonymous changes in gidB and rpsL, while ofloxacin resistance is conferred by such changes in $\operatorname{gyr} A$ and $\operatorname{gyr} B$. Finally, non-synonymous substitutions in $p n c A, r p o B$, and $k a t G$ confer resistance to pyrazinamide, rifampicin, and isoniazid, respectively.

In Siberia, a nucleotide substitution at codon 531 (S531L) in rpoB is dominant in rifampicin-resistant isolates. Mutations in other codons of this gene are less common, but are associated with lower relative fitness in isolates carrying this mutation compared with those carrying the wild-type gene $[27,28]$. In addition, it is worth noting that there is a relationship between the minimum inhibitory concentration of rifampicin and the presence of a mutation in the core region of rpoB. It was found that a high degree of resistance to rifampicin ( $\mathrm{MIC} \geq 50 \mu \mathrm{g} / \mathrm{ml}$ ) was observed in isolates which have mutations in codons 513,522 , and 531 . In contrast, a low degree of drug-resistance (MIC $\geq 12.5 \mu \mathrm{g} / \mathrm{ml}$ ) is conferred by nucleotide substitutions in codons 514,521 , 533 [29]. Mutations in codon 516 are also associated with a high degree of resistance ( $\mathrm{MIC} \geq 64 \mu \mathrm{g} / \mathrm{ml}$ ) [30,31]. Although some studies report similar results, H526L and H526N mutations are the exception; in these cases, the MIC values did not exceed 8 and $16 \mu \mathrm{g} / \mathrm{ml}$, respectively. A replacement mutation (L533P) was associated with MIC > $32 \mu \mathrm{g} / \mathrm{ml}$. Interestingly, Zhou et al. showed that replacement mutations in codons 526, 531, 532, 533 and 563 of rpoB in E.coli destabilize the promoter initiation complex which correspond to a range of transcription activity at these promoters at different growth rates [32].

The most common mutation for isoniazid resistance in the XDR strains was at codon 315 of the katG gene, thus correlating with the data from other studies [33]. This mutation was found among all of the isolates analyzed. Isoniazid resistance can also be caused by changes in the $\operatorname{ahpC}$, inhA, kasA and $\operatorname{oxy} R$ genes and it may be necessary to study these genes to investigate the molecular basis for isoniazid resistance in our XDR M. tuberculosis isolates [34].

The dominant mutations in the rpsL gene, which is involved in resistance to streptomycin, lead to amino acid substitutions in codons K43R and K88R. It is worth 
noting that the mutation at codon $43(\mathrm{~K} \rightarrow \mathrm{R})$ is strongly associated with high-level resistance to streptomycin, which worsens the prognosis for patients undergoing treatment for infection with $M$. tuberculosis carrying this mutation.

Resistance to the aminoglycosides amikacin and kanamycin and to capreomycin is thought to be associated with mutations in the $16 \mathrm{~S}$ rRNA gene ( $r r s)$. Mutations in rRNA 16S (rrs) at position 1401 are associated with the development of high resistance to these drugs, and this mutation was common in our dataset (66\%). The tlyA gene, coding for cytotoxin/hemolysin, is involved in resistance to aminoglycosides and capreomycin as well, but analysis of this gene was not informative because only 10 isolates had synonymous mutations (L11L).

The most common mutations for ofloxacin resistance were in the gyrA gene at codons 94 and 90, the former of which had the highest frequency of mutation (33\%). This is consistent with reports on XDR strains from Pakistan, India, China, the United States, and Germany [35-38], although in other regions different distributions of mutations may occur [39]. While the sequence change at codon 94 exhibited the highest variability, $63.3 \%$ of the XDR strains had a mutation at codon 95 of the gyrA gene; however, this mutation does not contribute to ofloxacin resistance and instead serves as an evolutionary marker for classification of $M$. tuberculosis strains into three principal genetic groups (PGGs) [40]. Hence, the ACC polymorphism at codon 95 confirms the PGG1 and PGG2 grouping [41]. In contrast, we found no mutations in $g y r B$.

The $p n c A$ gene, which encodes pyrazinamidase, hydrolyzes pyrazinamide to pyrazinoic acid, the latter in turn communicates with the $30 \mathrm{~S}$ ribosomal protein S1 (RpsA), thus the protein cannot bind to tmRNA molecules that inhibit trans translation in mycobacteria [42]. It remains unclear why there is a variety of mutations in the absence of any common mutations in this gene. One hypothesis that may explain the wide variety of nucleotide substitutions is that because its protein product is small (186 amino acids), each mutation may adversely affect its function [3]. This requires further study.

Thus, sequence analysis of the hot spot regions of various genetic loci revealed that the most common mutations among the XDR isolates were S531L of RpoB, S315T of KatG, various mutations in codon 94 of $g y r A$ and the A90V substitution in the GyrA protein, K43R of RpsL, and 1401 $\mathrm{A} \rightarrow \mathrm{G}$ of $\mathrm{rrs}$ for rifampicin, isoniazid, ofloxacin, streptomycin and kanamycin/capreomycin resistance, respectively. It is likely that these major mutations do not have a large effect on bacterial fitness [28]. Other studies have also reported similar mutations among XDR-TB isolates from different countries. It is possible that the disagreement between the genotypic and phenotypic resistance to ofloxacin and amikacin/kanamycin/capreomycin we observed may be caused by other mutations in regions distinct from the currently known target regions in these drugs [43]. In addition, mycobacterial cultures may also comprise a mixed population of resistant and sensitive bacteria [44] and, therefore, DNA extracted from specimens may contain lower levels of the resistant genotype, leading to a false low detection rate for the specimen. It should be noted that there are also mutations that are responsible for the formation of low level resistance to particular drugs. Nevertheless, sequencing the regions of genes responsible for the development of resistance to anti-TB drugs can be a convenient way to quickly identify drug resistance, thus enabling selection of effective drugs for treatment of the disease.

\section{Conclusions}

Identification of Beijing family $M$. tuberculosis isolates that are extensively drug-resistant and have high transmissibility and virulence highlights the need for early and rapid detection methods for this pathogen. Such isolates can be characterized using VNTR-typing and deligotyping methods. Deligotyping is a simple and convenient method for pre-screening large numbers of samples in epidemiological research, but the method has low discriminatory power. Evaluation of genetic diversity in M. tuberculosis strains circulating within an area will enable authorities to adopt effective measures to prevent the spread of infection, as well as providing basic information about the relationship between genetic diversity and virulence and immunity in the host. Armed with such information, it may be possible to determine how genetic diversity contributes to the global distribution of MDR and XDR in $M$. tuberculosis. It is obvious that there are epistatic interactions between the different mutations associated with the emergence of drug resistance, the genetic environment, and compensatory mutations, but understanding these complex relationships will require further research. DNA sequencing has revealed the presence of major mutations in the genes responsible for the emergence of resistance to the major anti-TB drugs. It is hoped that in the future, identification of $M$. tuberculosis drug resistant isolates and a description of their phenotypic properties will inform selection of more effective drugs against TB in the complex epidemiological situations that exist in Western and Eastern Siberia.

\section{Ethical approval}

Ethical approval was obtained from the Bioethical Committee of Institute of Chemical Biology and Fundamental Medicine Siberian Academy of Science. Informed consent was obtained from each patient in the study.

Competing interests

The authors declare that they have no competing interests. 


\section{Authors' contributions}

MAD carried out the molecular genetic studies, drafted the manuscript, and performed the statistical analysis. OIA, AGC, and TIP participated in sample collection and antibiotic susceptibility testing. EAK conducted the sequence alignments. MLF conceived the study and participated in its design and coordination. All authors have read and approved the final manuscript.

\section{Acknowledgements}

We thank the staff of the Novosibirsk Research Institute of Tuberculosis for their support. We are particularly grateful to the bacteriologists, physicians, and nurses, as well as the patients who took part in the study.

\section{Funding}

The work was supported by funding from the Program of the Presidium of Siberian Academy of Science №5 (Project №43), and from the Russian federal program (State Contract No 11.519.11.2013).

\section{Author details}

${ }^{1}$ Institute of Chemical Biology and Fundamental Medicine (ICBFM), Siberian Branch of The Russian Academy of Sciences (SB RAS), Novosibirsk, Russia. ${ }^{2}$ Novosibirsk State University (NSU), Novosibirsk, Russia. ${ }^{3}$ Ministry of Public Health and Social Development of The Russian Federation (NRIT), Novosibirsk Research Institute of Tuberculosis, Novosibirsk, Russia.

Received: 22 October 2013 Accepted: 29 August 2014

Published: 3 September 2014

\section{References}

1. World Health Organization: Global Tuberculosis Report; 2012. http://apps.who. int/iris/bitstream/10665/75938/1/9789241564502 eng.pdf.

2. Borrell $S$, Gagneux S: Infectiousness, reproductive fitness and evolution of drug-resistant Mycobacterium tuberculosis. Int I Tuberc Lung Dis 2009, 13:1456-1466.

3. Ramaswamy S, Musser JM: Molecular genetic basis of antimicrobial agent resistance in Mycobacterium tuberculosis: 1998 update. Tuber Lung Dis 1998, 79:3-29.

4. Nachamkin I, Kang C, Weinstein MP: Detection of resistance to isoniazid, rifampin, and streptomycin in clinical isolates of Mycobacterium tuberculosis by molecular methods. Clin Infect Dis 1997, 24:894-900.

5. Maus CE, Plikaytis BB, Shinnick TM: Mutation of tlyA confers capreomycin resistance in Mycobacterium tuberculosis. Antimicrob Agents Chemother 2005, 49:571-577.

6. Van Soolingen D: Molecular epidemiology of tuberculosis and other mycobacterial infections: main methodologies and achievements. J Intern Med 2001, 249:1-26.

7. Frothingham R, Meeker-O'Connell WA: Genetic diversity in the Mycobacterium tuberculosis complex based on variable numbers of tandem DNA repeats. Microbiology 1998, 144(Pt 5):1189-1196.

8. Supply P, Mazars E, Lesjean S, Vincent V, Gicquel B, Locht C: Variable human minisatellite-like regions in the Mycobacterium tuberculosis genome. Mol Microbiol 2000, 36:762-771.

9. Tsolaki AG, Hirsh AE, DeRiemer K, Enciso JA, Wong MZ, Hannan M, de la Salmoniere YO G, Aman K, Kato-Maeda M, Small PM: Functional and evolutionary genomics of Mycobacterium tuberculosis: insights from genomic deletions in 100 strains. Proc Natl Acad Sci U S A 2004, 101:4865-4870.

10. Tsolaki Gagneux S, Pym AS, de la Salmoniere YO G, Kreiswirth BN, Van Soolingen D, Small PM: Genomic deletions classify the Beijing/W strains as a distinct genetic lineage of Mycobacterium tuberculosis. $J$ Clin Microbiol 2005, 43:1-7.

11. Rand WM: Objective criteria for the evaluation of clustering methods. J Am Stat Assoc 1971, 66:846-850.

12. Feil EJ, Li BC, Aanensen DM, Hanage WP, Spratt BG: eBURST: inferring patterns of evolutionary descent among clusters of related bacterial genotypes from multilocus sequence typing data. J Bacteriol 2004, 186:1518-1530.

13. Hunter PR, Gaston MA: Numerical index of the discriminatory ability of typing systems: an application of Simpson's index of diversity. J Clin Microbiol 1988, 26:2465-2466.

14. de la Salmoniere YO G, Kim CC, Tsolaki AG, Pym AS, Siegrist MS, Small PM: High-throughput method for detecting genomic-deletion polymorphisms. J Clin Microbiol 2004, 42:2913-2918.
15. Allix-Béguec C, Harmsen D, Weniger T, Supply P, Niemann S: Evaluation and strategy for use of MIRU-VNTRplus, a multifunctional database for online analysis of genotyping data and phylogenetic identification of Mycobacterium tuberculosis complex isolates. J Clin Microbiol 2008, 46:2692-2699.

16. Mazars E, Lesjean S, Banuls AL, Gilbert M, Vincent V, Gicquel B, Tibayrenc M, Locht C, Supply P: High-resolution minisatellite-based typing as a portable approach to global analysis of Mycobacterium tuberculosis molecular epidemiology. Proc Natl Acad Sci U S A 2001, 98:1901-1906.

17. Mokrousov I, Narvskaya O, Vyazovaya A, Millet J, Otten T, Vishnevsky B, Rastogi N: Mycobacterium tuberculosis Beijing genotype in Russia: in search of informative variable-number tandem-repeat loci. J Clin Microbiol 2008, 46:3576-3584

18. Mokrousov I: Genetic geography of Mycobacterium tuberculosis Beijing genotype: a multifacet mirror of human history? Infect Genet Evol 2008, 8:777-785.

19. Mokrousov I, Ly HM, Otten T, Lan NN, Vyshnevskyi B, Hoffner S, Narvskaya O: Origin and primary dispersal of the Mycobacterium tuberculosis Beijing genotype: clues from human phylogeography. Genome Res 2005, 15:1357-1364

20. Huyen MNT, Kremer K, Lan NTN, Cobelens FGJ, Buu TN, Dung NH, Caws M, Tiemersma EW, van Soolingen D: Mixed tuberculosis infections in rural South Vietnam. J Clin Microbiol 2012, 50:1586-1592.

21. Mostrom P, Gordon M, Sola C, Ridell M, Rastogi N: Methods used in the molecular epidemiology of tuberculosis. Clin Microbiol Infect 2002, 8:694-704.

22. Dymova MA, Nikonov SD, Akulinushkin Al, Ogirenko AP, Filipenko ML: Mycobacterium tuberculosis Beijing family in Novosibirsk oblast: the prevalence of patients with severe forms of the disease and the connection of multi-drug resistance. Vestn NSU Biol Clin Med 2008, 6(3):106-109.

23. Poudel A, Maharjan B, Nakajima C, Fukushima Y, Pandey BD, Beneke A, Suzuki Y: Characterization of extensively drug-resistant Mycobacterium tuberculosis in Nepal. Tuberculosis (Edinb) 2012, 56(6):2831-2836.

24. Lasunskaia E, Ribeiro SC, Manicheva O, Gomes LL, Suffys PN, Mokrousov I, Ferrazoli L, Andrade MR, Kritski A, Otten T, Kipnis TL, da Silva WD, Vishnevsky B, Oliveira MM, Gomes HM, Baptista IF, Narvskaya O: Emerging multidrug resistant Mycobacterium tuberculosis strains of the Beijing genotype circulating in Russia express a pattern of biological properties associated with enhanced virulence. Microbes Infect 2010, 12:467-475.

25. David S, Portugal C, Antunes A, Cardoso A, Calado A, Barros V, Sancho L: [Molecular identification using Spoligotyping of strains from the Mycobacterium tuberculosis complex isolated from the Hospital Fernando Fonseca]. Rev Port Pneumol 2004, 10:195-204.

26. Lipin MY, Stepanshina VN, Shemyakin IG, Shinnick TM: Association of specific mutations in katG, rpoB, rpsL and rrs genes with spoligotypes of multidrug-resistant Mycobacterium tuberculosis isolates in Russia. Clin Microbiol Infect 2007, 13:620-626.

27. Billington OJ, McHugh TD, Gillespie SH: Physiological cost of rifampin resistance induced in vitro in Mycobacterium tuberculosis. Antimicrob Agents Chemother 1999, 43:1866-1869.

28. Gagneux S, Long CD, Small PM, Van T, Schoolnik GK, Bohannan BJ: The competitive cost of antibiotic resistance in Mycobacterium tuberculosis. Science (80- ) 2006, 312:1944-1946.

29. Taniguchi H, Aramaki H, Nikaido Y, Mizuguchi Y, Nakamura M, Koga T, Yoshida S: Rifampicin resistance and mutation of the rpoB gene in Mycobacterium tuberculosis. FEMS Microbiol Lett 1996, 144:103-108.

30. Bodmer T, Zurcher G, Imboden P, Telenti A: Mutation position and type of substitution in the beta-subunit of the RNA polymerase influence in-vitro activity of rifamycins in rifampicin-resistant Mycobacterium tuberculosis. J Antimicrob Chemother 1995, 35:345-348.

31. Ohno H, Koga H, Kohno S, Tashiro T, Hara K: Relationship between rifampin MICs for and rpoB mutations of Mycobacterium tuberculosis strains isolated in Japan. Antimicrob Agents Chemother 1996, 40:1053-1056.

32. Zhou YN, Jin DJ: The rpoB mutants destabilizing initiation complexes at stringently controlled promoters behave like "stringent" RNA polymerases in Escherichia coli. Proc Natl Acad Sci U S A 1998, 95:2908-2913.

33. Campbell PJ, Morlock GP, Sikes RD, Dalton TL, Metchock B, Starks AM, Hooks DP, Cowan LS, Plikaytis BB, Posey JE: Molecular detection of mutations associated with first- and second-line drug resistance compared with 
conventional drug susceptibility testing of Mycobacterium tuberculosis. Antimicrob Agents Chemother 2011, 55:2032-2041.

34. Cardoso RF, Cooksey RC, Morlock GP, Barco P, Cecon L, Forestiero F, Leite $C Q$, Sato DN, Shikama Mde L, Mamizuka EM, Hirata RD, Hirata MH:

Screening and characterization of mutations in isoniazid-resistant Mycobacterium tuberculosis isolates obtained in Brazil. Antimicrob Agents Chemother 2004, 48:3373-3381.

35. Ali A, Hasan R, Jabeen K, Jabeen N, Qadeer E, Hasan Z: Characterization of mutations conferring extensive drug resistance to Mycobacterium tuberculosis isolates in Pakistan. Antimicrob Agents Chemother 2011, 55:5654-5659.

36. Ajbani K, Rodrigues C, Shenai S, Mehta A: Mutation detection and accurate diagnosis of extensively drug-resistant tuberculosis: report from a tertiary care center in India. J Clin Microbiol 2011, 49:1588-1590.

37. Feuerriegel S, Cox HS, Zarkua N, Karimovich HA, Braker K, Rüsch-Gerdes S, Niemann S: Sequence analyses of just four genes to detect extensively drug-resistant Mycobacterium tuberculosis strains in multidrug-resistant tuberculosis patients undergoing treatment. Antimicrob Agents Chemother 2009, 53:3353-3356

38. Sun Z, Chao Y, Zhang X, Zhang J, Li Y, Qiu Y, Liu Y, Nie L, Guo A, Li C: Characterization of extensively drug-resistant Mycobacterium tuberculosis clinical isolates in China. J Clin Microbiol 2008, 46:4075-4077.

39. Perdigão J, Macedo R, Malaquias A, Ferreira A, Brum L, Portugal I: Genetic analysis of extensively drug-resistant Mycobacterium tuberculosis strains in Lisbon, Portugal. J Antimicrob Chemother 2010, 65:224-227.

40. Sreevatsan S, Pan X, Stockbauer KE, Connell ND, Kreiswirth BN, Whittam TS, Musser JM: Restricted structural gene polymorphism in the Mycobacterium tuberculosis complex indicates evolutionarily recent global dissemination. Proc Natl Acad Sci U S A 1997, 94:9869-9874.

41. Gutierrez MC, Ahmed N, Willery E, Narayanan S, Hasnain SE, Chauhan DS, Katoch VM, Vincent V, Locht C, Supply P: Predominance of ancestral lineages of Mycobacterium tuberculosis in India. Emerg Infect Dis 2006, 12:1367-1374

42. Kalinda AS, Aldrich CC: Pyrazinamide: a frontline drug used for tuberculosis: molecular mechanism of action resolved after 50 years? ChemMedChem 2012, 7:558-560.

43. Evans J, Segal H: Novel multiplex allele-specific PCR assays for the detection of resistance to second-line drugs in Mycobacterium tuberculosis. J Antimicrob Chemother 2010, 65:897-900.

44. Baldeviano-Vidalón GC, Quispe-Torres N, Bonilla-Asalde C, Gastiaburú-Rodriguez D, Pro-Cuba JE, Llanos-Zavalaga F: Multiple infection with resistant and sensitive M. tuberculosis strains during treatment of pulmonary tuberculosis patients. Int J Tuberc Lung Dis 2005, 9:1155-1160.

doi:10.1186/1471-2334-14-478

Cite this article as: Dymova et al:: Characterization of extensively

drug-resistant Mycobacterium tuberculosis isolates circulating in Siberia. BMC Infectious Diseases 2014 14:478.

\section{Submit your next manuscript to BioMed Central and take full advantage of:}

- Convenient online submission

- Thorough peer review

- No space constraints or color figure charges

- Immediate publication on acceptance

- Inclusion in PubMed, CAS, Scopus and Google Scholar

- Research which is freely available for redistribution

Submit your manuscript at www.biomedcentral.com/submit
C Biomed Central 